\title{
THE USE OF FUZZY RULE-BASED SYSTEMS IN DETERMINING HORIZONTAL PCO PARAMETERS OF GNSS ANTENNAS
}

\section{Obtenção dos parâmetros horizontais do PCO de antenas GNSS por meio de sistemas baseado em regras fuzzy}

Nassau de Nogueira Nardez ${ }^{1}$ - ORCID: 0000-0002-5393-2050

Cláudia Pereira Krueger ${ }^{1}$ - ORCID: 0000-0002-4839-1317

Rosana Sueli da Motta Jafelice ${ }^{2}$ - ORCID: 0000-0001-8489-3974

Marcio Augusto Reolon Schmidt ${ }^{1}$ - ORCID: 0000-0003-2716-2360

${ }^{1}$ Universidade Federal do Paraná - UFPR, Programa de Pós-graduação em

Ciências Geodésicas - PPGCG, Curitiba - PR, Brasil.

E-mail:nardeznassau@ufu.br; ckrueger@ufpr.br; marcio.schmidt@ufu.br

${ }^{2}$ Universidade Federal de Uberlândia - UFU, Programa de Pós-Graduação em Matemática - PPMAT, Uberlândia - MG, Brasil.

E-mail:rmotta@ufu.br

Received in September $12^{\text {th }}, 2017$

Accepted in May $26^{\text {th }}, 2018$

\section{Abstract:}

Knowledge concerning Phase Center Offset (PCO) is an important aspect in the calibration of GNSS antennas and has a direct influence on the quality of high precision positioning. Studies show that there is a correlation between meteorological variables when determining the north $(\mathrm{N})$, east (E) and vertical Up (H) components of PCO. This article presents results for the application of Fuzzy Rule-Based Systems (FRBS) for determining the position of these components. The function Adaptive Neuro-Fuzzy Inference Systems (ANFIS) was used to generate FRBS, with the PCO components as output variables. As input data, the environmental variables such as temperature, relative humidity and precipitation were used; along with variables obtained from the antenna calibration process such as Positional Dilution of Precision and the multipath effect. An FRBS was constructed for each planimetric $N$ and $E$ components from the carriers $L 1$ and $L 2$, using a training data set by means of ANFIS. Once the FRBS were defined, the verification data set was applied, the components obtained by the FRBS and Antenna Calibration Base at the Federal University of Paraná were compared. For planimetric components, the difference was less than $1.00 \mathrm{~mm}$, which shows the applicability of the method for horizontal components.

Keywords: GNSS Antenna Calibration; Environmental Variables; Fuzzy Sets; ANFIS.

How to cite this article: Nardez, N. N. et al. The use of fuzzy rule-based systems in determining horizontal PCO parameters of GNSS antennas. Bulletin of Geodetic Sciences, Vol. 24 (3), 367-382, Jul-Sept, 2018. 


\section{Resumo:}

O conhecimento do deslocamento do centro de fase (PCO) é um importante aspecto da calibração de antenas GNSS e tem influência direta na qualidade do posicionamento de alta precisão. Estudos mostram que existe correlação entre variáveis meteorológicas na determinação das componentes: norte $(\mathrm{N})$, leste $(\mathrm{E})$ e vertical $(\mathrm{H})$ do PCO. Este artigo apresenta resultados da aplicação de Sistemas Baseados em Regras Fuzzy (SBRF) na determinação das componentes horizontais N e E. Utilizou-se a função Adaptive Neuro-Fuzzy Inference Systems (ANFIS) para gerar os SBRF tendo as componentes do PCO como variáveis de saída. Como dados de entrada utilizaram-se as variáveis ambientais temperatura, umidade relativa do ar e precipitação, variáveis do processamento de calibração de antenas como Positional Dilution of Precision e efeito multicaminho. Construiu-se um SBRF para cada componente horizontal das portadoras L1 e L2 utilizando-se um conjunto de dados de treinamento por meio da ANFIS. Definidos os SBRF, aplicou-se o conjunto de dados de verificação, comparou-se as componentes obtidas pelo SBRF e pela Base de Calibração de Antenas da Universidade Federal do Paraná. Para componentes planimétricas as diferenças foram menores que $1,00 \mathrm{~mm}$, o que mostra a aplicabilidade do método para as componentes horizontais.

Palavras-chave: Calibração de Antenas GNSS; Variáveis Ambientais; Conjuntos Fuzzy; ANFIS.

\section{Introduction}

In many geodesic and geophysical applications, it is of the upmost importance to obtain the point coordinates with a high degree of accuracy. As for example in the implementation and maintenance of geodesic networks of the first-order, in the monitoring of sea level, positions that require millimeter precision when determining the velocity of reference stations (Rothacher and Mader, 2002). As well as verifying the demand for the obtainment of high precision coordinates in the monitoring of structures, the monitoring of risk areas, in tectonic plate movement among other applications.

In order to obtain precision at the millimeter level in positioning on the surface of the earth by means of GNSS observations, it is fundamentally necessary the minimization or elimination of systematic errors; these errors may be parameterized or reduced by appropriate processing techniques (Monico, 2008). Errors such as those arising from the phase center of the antenna connected to the receptor and the multipath effect needs to be known and taken into consideration. The occurrence of multipath depends on factors, such as refractivity from the center of the antenna position, characteristics of the antenna and the techniques employed on the receptors for reducing reflected signals.

The phase center (PC) consists of a virtual point in the antenna where the reception of signals emitted by satellites occurs and the measurements of the signals are referenced. This virtual point does not coincide with the geometric center of the antenna but varies according to the intensity and direction of the signals that arrive at the antenna (Seeber, 2003; Monico, 2008). The displacements of the phase center are divided into two components: Phase Center Offset (PCO) and Phase Center Variation (PCV). Mader (1999) states that the neglecting of these values may lead to errors in the horizontal components, in as much as two centimeters and in the vertical component by as much as ten centimeters, which is also confirmed by Leick (2004). 
However, the difficulty is in processing and evaluating all these parameters. One notes that the techniques and artificial intelligence models, for example, the fuzzy set theory associated with artificial neural networks allows for the connecting of data from distinct natures and obtain through inference, values from a database. For example, a Fuzzy Rule-Based Systems (FRBS) can be obtained using the function Adaptive Neuro-Fuzzy Inference Systems (ANFIS) from Matlab, wherein, by means of a dataset the ANFIS function identifies the membership functions, the rule base and the FRBS output parameters.

Thus, the ANFIS technique was applied from a database in order to define a FRBS. This system allows for the relating of meteorological parameters to those that indicate the relative processing quality of the GPS data arising from the antenna calibration process, and thus, obtain the values of the planimetric components: North (N) and East (E) of the PCO for GPS antennas. The vertical component Up $(\mathrm{H})$ will be treated in a separate paper.

The hypothesis of this research is based on the premise that it is possible to model a FRBS for estimating the relationship between environmental parameters, which affect the calibration process (Huinca and Krueger, 2011; 2012) and the parameters resulting from the relative calibration for the calculation of the PCO from GNSS antennas. To reach this goal, the types and quantities of membership functions appropriate for FRBS were determined using ANFIS in relation to the relative calibration results, along with the evaluation of the input variables in the PCO model.

The PCO calibration tests were performed by the calibration of signal receiver antennas GNSS, a Leica Geosystems antenna model LEIAX1202GG at Calibration Base of Antennas GNSS installed at UFPR (BCAL/UFPR) during two months. Inspired by Ferreira (2012), the FRBS were written in the Matlab environment and the results show it is possible to model the PCO components, thus contributing to a reduction in calibration costs, since after being calibrated a few times, one can predict the parameters, while presenting the potential to minimize the direct calibration of the antenna at its base.

\section{Theoretical Foundation}

The electronic phase center of an antenna is a virtual point, where all the measurements derived from GNSS signals are referenced. The phase center can be divided into two components, the displacement of the phase center (PCO), which consists of a vector originating on the ARP and mean phase center extremity (MPC), along with the Phase Center Variation (PCV), which is dependent upon the signal incidence angle (Seeber, 2003; Freiberger Junior, 2007). Figure 1 illustrates the position of the $\overrightarrow{\mathrm{P}}$ vector (PCO), MPC, as well as the PCV. 


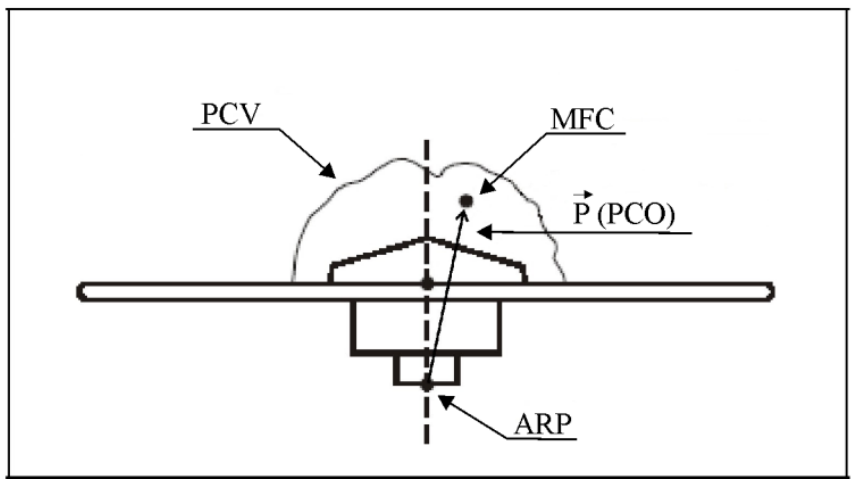

Figure 1: Position and phase center variance of the GNSS antenna.

Source: Adapted from Freiberger Junior (2007).

Thus, the vector PCO is defined by its Cartesian coordinates given through $\mathrm{N}$ and $\mathrm{E}$ that are the horizontal components in the directions North and East, respectively, and the vertical component $\mathrm{H}$. The determination of the PCO performed through relative calibration in the field consists of observing a known short baseline for a long period of time and determining its inherent parameters (Freiberger Junior, 2007). Figure 2 illustrates this procedure in the BCAL/UFPR, with two antennas positioned on pillars that create a baseline of approximately five meters. Observations are made for twenty-four hours, providing coverage of satellite data along the antenna horizon (Wanninger and May 2000). Due to the short baseline between the antennas, it is assumed that the influence of orbital errors from the ionosphere and the troposphere become negligible (Freiberger Junior, 2007).

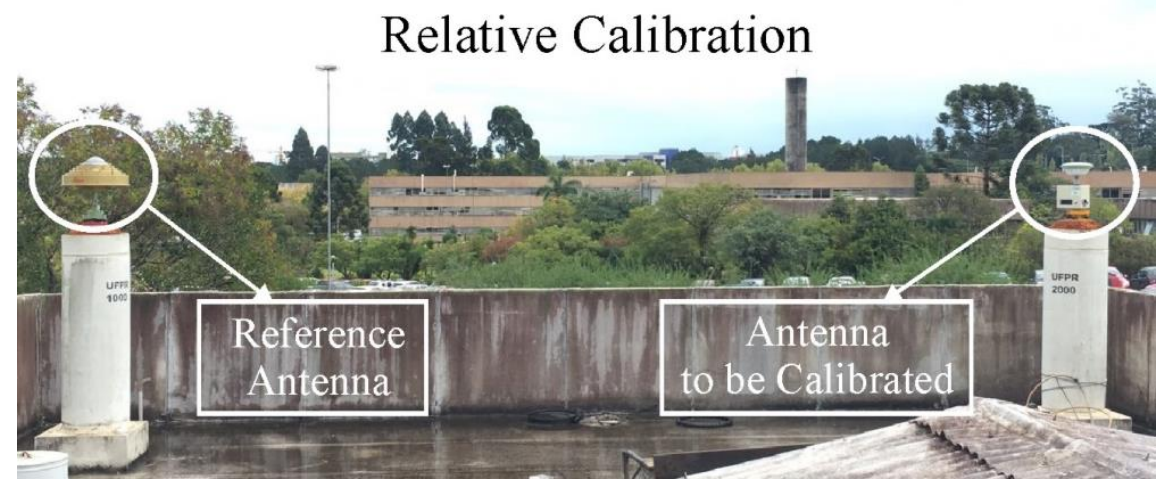

Figure 2: Relative calibration at BCAL/UFPR.

Source: Adapted from Krueger et al. (2012).

According to Wübbena et al. (2000), the reference antenna calibration parameters should be known a priori, including multipath error minimization, in order to obtain reliable calibration parameters. The multipath effect is minimized by using a device called, in German, DrehRumBum (DRB). It performs horizontal rotations in distinct azimuths during the measurements in the antenna to be calibrated. Thus, it generates superabundant observations that contribute to minimize the multipath effect (Frevert et al., 2003). 
In this study, the multipath effect was measured by the software TEQC (Translate Edit Quality Check) developed by the University NAVSTAR Consortium (Unavco, 2017). This software allows one to analyze the level of variation of the multipath in a station using the MP1 and MP2 values that refer to the multipath in the carriers L1 and L2 (Souza et al., 2005). Linear combinations for MP1 and MP2 are described in Rocken et al. (1995). In the following section we define fuzzy sets and the FRBS structure.

\subsection{Fuzzy Rule-Based System}

Negnevitsky (2005) defines FRBS as a process of mapping from a given input to an output using the theory of fuzzy sets. The fuzzy set theory is characterized by its operations and relationships between subsets belonging to a universe (Zadeh, 1965), a subset $A$ of the universe set $X$ is defined in terms of a membership function, as each element $x$ of $X$ associates a number $\mu(x)$, between zero and one, called membership degree (Negnevitsky, 2005). A fuzzy rule-based system is composed of four functional blocks (Figure 3 ).

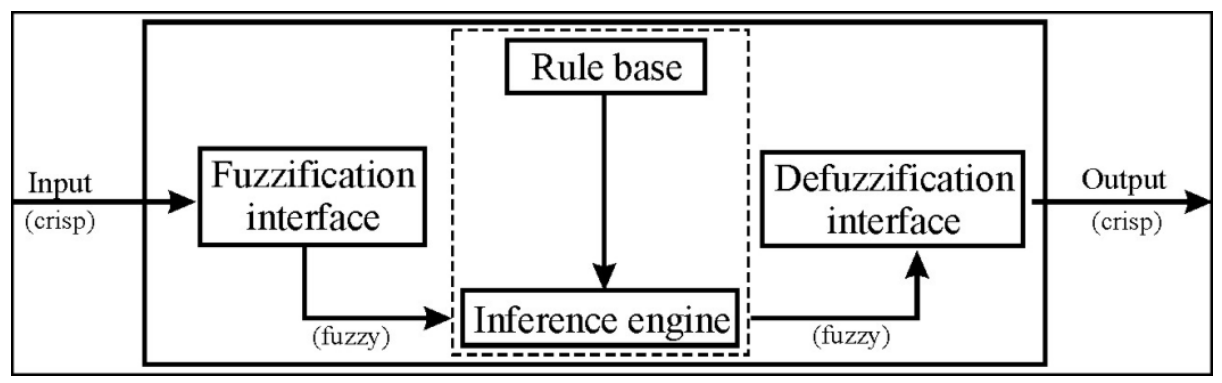

Figure 3: Architecture of a FRBS.

Source: adapted from Jang (1993).

According to Jang (1993) the four functional blocks are: fuzzification - interface which transforms the crisp inputs into degrees of match with linguistic values; a rule base - containing a number of fuzzy if-then rules; inference engine - unit which performs the inference operations on the rules; and defuzzification interface - interface which transforms the fuzzy results of the inference into a crisp output.

In the next section, we present the ANFIS structure of the Matlab toolbox, where, through the training dataset, it identifies the domains of membership functions, the rule base, and the FRBS output parameters.

\subsection{Adaptive Neuro-Fuzzy Inference System}

The neuro-fuzzy system ANFIS is a training routine for fuzzy inference systems of the TakagiSugeno type (Takagi and Sugeno, 1985). From a dataset, the ANFIS system uses a learning algorithm for identifying the system parameters based on fuzzy rules (Bystrov and Westin, 2015). Figure 3 illustrates the ANFIS architecture that considers two inputs $x$ and $y$ and one output $z$. 
One then supposes that the rule base contains two fuzzy if-then rules of Takagi-Sugeno's type: Rule 1: If $x$ is $A_{1}$ and $y$ is $B_{1}$, then $f 1=p_{1} x+q_{1} y+r_{1}$, Rule 2: If $x$ is $A_{2}$ and $y$ is $B_{2}$, then $f 2=p_{2} x+q_{2} y$ $+r_{2}$.

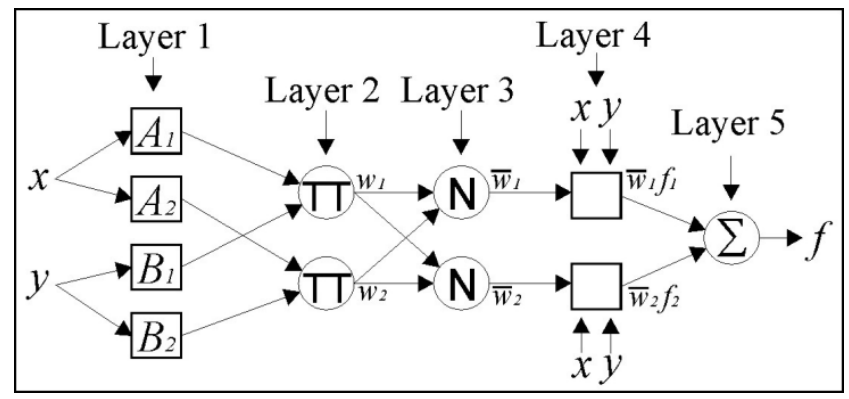

Figure 4: Adaptive network ANFIS.

Source: adapted from Jang et al. (1997).

According to com Jang et al. (1997) in layer 1 every node $i$ is a square node with a node function:

$$
O_{i}^{1}=\mu_{A_{i}}(x)
$$

Where $x$ is the input to node $i$, and $A_{i}$ is the linguistic label (e.g.: low, medium, high, etc.) associated with this node function. $O_{i}{ }^{1}$ is the membership function of $A_{i}$ and it specifies the degree to which the given $x$ satisfies the quantifier $A_{i}$.

In layer 2 , every node is a circle node labeled $\Pi$ which multiplies the incoming signals and sends the product out, e.g.:

$$
w_{i}=\mu_{A_{i}}(x) \times \mu_{B_{i}}(y), i=1,2 .
$$

Each node output represents the firing strength of a rule. In layer 3, every node is a circle node labeled $N$. The $i^{\text {th }}$ node calculates the ratio of the firing strength of the $i^{\text {th }}$ rule to the sum of all the strengths of the firing rule:

$$
\bar{w}_{i}=\frac{w_{i}}{w_{1}+w_{2}}, i=1,2
$$

Outputs of this layer will be called normalized strengths (Jang, 1993). Every node i in layer 4 is a square node with a node function:

$$
O_{i}^{4}=\bar{w}_{i} f_{i}=\bar{w}_{i}\left(p_{i} x+q_{i} y+r_{i}\right)
$$


Where $\bar{w}_{i}$ is the output of layer 3 , and $\left(p_{i}, q_{i}\right.$ e $\left.r_{i}\right)$ is the parameter set or consequent parameters (Jang, 1993; Jang et al., 1997). In layer 5 , the single node is a circle node labeled $\sum$ that computes the overall output as the summation of all incoming signals, e.g.:

$$
O_{i}^{5}=\sum_{i} \bar{w}_{i} f_{i}=\frac{\sum_{i} w_{i} f_{i}}{\sum_{i} w_{i}}
$$

In other words, the output is obtained by a weighted average value.

The learning algorithm can be expressed as linear combinations of the consequent parameters; the output can be rewritten as:

$$
\begin{aligned}
& f=\frac{w_{1}}{w_{1}+w_{2}} f_{1}+\frac{w_{2}}{w_{1}+w_{2}} f_{2} \\
& =\bar{w}_{1} f_{1}+\bar{w}_{2} f_{2} \\
& =\left(\bar{w}_{1} x\right) p_{1}+\left(\bar{w}_{1} y\right) q_{1}+\left(\bar{w}_{1}\right) r_{1} \\
& +\left(\bar{w}_{2} x\right) p_{2}+\left(\bar{w}_{2} y\right) q_{2}+\left(\bar{w}_{2}\right) r_{2},
\end{aligned}
$$

Which is linear in the consequent parameters $p_{1}, q_{1}, r_{1}, p_{2}, q_{2}$ and $r_{2}$ (Jang, 1993).

\section{Materials and Methods}

The proposed application of the ANFIS technique was to determine FRBS, in order to relate the meteorological parameters temperature, relative humidity and precipitation with the variables obtained during the antenna calibration process as the Positional Precision Dilution and the multipath effect. Therefore, resulting in the obtainment of the values for the planimetric components: North (N) and East (E) of the PCO for GPS antennas. Despite the antenna used in this research being a LEIAX1202GG antenna, the tests were performed using only data from the GPS system.

A series of calibrations were performed at BCAL/UFPR for the selected antenna over March and April of 2015. During the calibration process performed on the GNSS antennas, the relative calibration method was applied at an absolute level. In this process, a Leica Geosystems antenna, model AR25 was used as a reference and it was installed onto the reference pillar, named as pillar 1000. The antenna used for the calibration tests, the LEIAX1202GG, was positioned over the DRB mechanism and both were installed onto the auxiliary pillar, named pillar 2000 (Figure 5). The time for each calibration series was 24-hour at a data collection rate of every 15 seconds. 


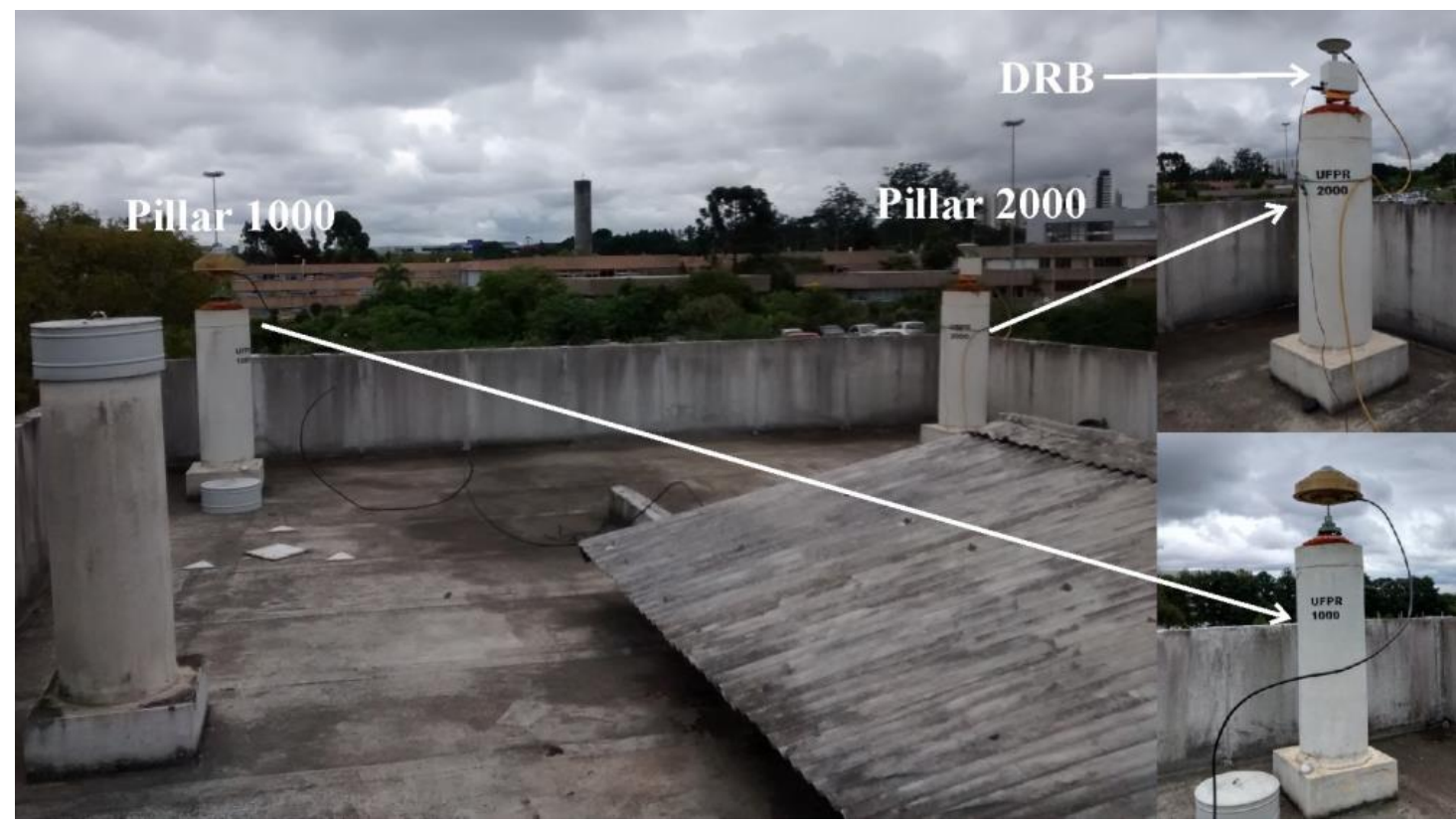

Figure 5: Relative calibration method in the field at BCAL/UFPR.

Source: adapted from Nardez (2015).

The relative coordinates $\mathrm{N}$ and $\mathrm{E}$ from the PCO were obtained for the carrier waves L1 and L2 using the software WaSoft/Kalib over the collected data. The data collected on Pillar 2000 were processed with TEQC for each of the calibration series performed, with the aim of obtaining the multipath levels for each of the carrier waves (L1 and L2).

The meteorological variables were obtained from the National Institute of Meteorology (INMET) reports for the respective days of the calibration series. The INMET monitoring station in Curitiba, called CURITIBA-A807, is located next to the BCAL/UFPR. It is assumed that the meteorological parameters for the two locations are the same, and still further, so too are the PDOP values extracted from the relative calibration reports, as well as the Multipath effect that correspond to each calibration series, for each of the wave carriers, $L 1$ and $L 2$, obtained by the TEQC software.

Using these data, a training data set was created and then a programming routine for training, adjusting and constructing a fuzzy rules-based inference system (SBRF) was elaborated in the MATLAB environment following the steps.

1) The domain intervals for each of the input variables temperature, relative humidity, precipitation, PDOP and the multipath effect were established. The values were taken from the whole data set obtained, and then the maximum and minimum values of each variable were inserted, defining, respectively, the maximum and minimum values of the domains (universes) of each variable.

2) Establishment of the number of membership functions for each of the input variables, which is equivalent to the number of fuzzy sets of the variables.

3) Definition of the type of membership function to represent the fuzzy sets of each variable. The types of membership function tested were: 'trapmf', 'gbellmf', 'trimf', 'gaussmf', 'gauss2mf', 'smf', 'zmf', 'psigmf', 'dsigmf', 'pimf' and 'sigmf'. 
4) Application of the ANFIS function to obtain the SBRF for each of the components of the PCO.

Approximately 330 tests were performed with the SBRFs created by ANFIS, each consisting of varying the number and type of membership functions, as well as the combination of input variables.

The criteria for choosing the definitive SBRFs that would provide us the PCO values were those that presented the lowest values of Relative Error by means of Euclidean Distance and Root Mean Square Error (RMSE) in the construction of the SBRF by ANFIS.

After the SBRFs were defined, the verification data were applied, that is, it inserts the values of the input variables for a specific day, and the system provides the value of the PCO component, so, we can compare the values of the PCO obtained by the SBRF with the PCO results obtained by the relative calibration for that day. According to Zeimetz and Kuhlmann (2008), this difference cannot be greater than $1 \mathrm{~mm}$.

\section{Results and Discussion}

Tables 1 and 2 present the training data were the PCO components are the result from the relative calibration in the field. On Table 1, one notes the values for the components of the PCO for L1 and L2.

Table 1: Training datasets (components of the PCO).

\begin{tabular}{cccccc}
\hline \multirow{2}{*}{ Series } & \multirow{2}{*}{ GPS day/year } & \multicolumn{2}{c}{ PCO components for L1 } & \multicolumn{2}{c}{ PCO components for L2 } \\
\cline { 3 - 6 } & & $\mathrm{N}(\mathrm{mm})$ & $\mathrm{E}(\mathrm{mm})$ & $\mathrm{N}(\mathrm{mm})$ & $\mathrm{E}(\mathrm{mm})$ \\
\hline 1 & $071 / 2015$ & 1.4 & -0.2 & -0.8 & 0.3 \\
2 & $072 / 2015$ & 1.5 & -0.6 & -0.6 & 0.5 \\
3 & $073 / 2015$ & 1.4 & -0.5 & -0.6 & 0.4 \\
4 & $074 / 2015$ & 1.3 & -0.2 & -0.7 & 0.3 \\
5 & $075 / 2015$ & 1.4 & -0.6 & -0.6 & 0.4 \\
6 & $076 / 2015$ & 1.4 & -0.7 & -0.7 & 0.5 \\
7 & $077 / 2015$ & 1.3 & -0.7 & -0.6 & 0.5 \\
8 & $078 / 2015$ & 1.3 & -0.7 & -0.6 & 0.4 \\
9 & $079 / 2015$ & 1.3 & -0.7 & -0.6 & 0.5 \\
10 & $097 / 2015$ & 1.4 & -0.6 & -0.6 & 0.4 \\
11 & $098 / 2015$ & 1.3 & -0.5 & -0.6 & 0.4 \\
\hline
\end{tabular}

The Table 2 presents the values of meteorological variables obtained from the National Institute of Meteorology reports, the PDOP extracted from the relative calibration reports and multipath values calculated by the TEQC software. 
Table 2: Training datasets (meteorological variables, PDOP and multipath).

\begin{tabular}{ccccccccc}
\hline \multirow{2}{*}{ Series } & \multirow{2}{*}{$\begin{array}{c}\text { GPS } \\
\text { day/year }\end{array}$} & $\begin{array}{c}\text { Temperature } \\
\left({ }^{\circ} \mathrm{C}\right)\end{array}$ & $\begin{array}{c}\text { Relative } \\
\text { Humidity }(\%)\end{array}$ & $\begin{array}{c}\text { Precipitation } \\
(\mathrm{mm})\end{array}$ & PDOP & \multicolumn{2}{c}{ Multipath (m) } \\
\cline { 3 - 5 } & & Average & Average & Maximum & & MP (L1) & MP (L2) \\
\hline 1 & $071 / 2015$ & 21.2 & 77.9 & 0.4 & 1.1 & 0.60 & 0.59 \\
2 & $072 / 2015$ & 21.6 & 76.4 & 14.6 & 1.1 & 0.62 & 0.70 \\
3 & $073 / 2015$ & 21.4 & 77.1 & 14.6 & 1.1 & 0.62 & 0.70 \\
4 & $074 / 2015$ & 21.0 & 82.1 & 10.4 & 1.1 & 0.56 & 0.71 \\
5 & $075 / 2015$ & 22.1 & 79.0 & 0.2 & 1.1 & 0.56 & 0.71 \\
6 & $076 / 2015$ & 20.8 & 84.5 & 9.0 & 1.1 & 0.65 & 0.65 \\
7 & $077 / 2015$ & 19.6 & 87.3 & 0.2 & 1.1 & 0.52 & 0.54 \\
8 & $078 / 2015$ & 18.8 & 81.2 & 0.0 & 1.1 & 0.51 & 0.55 \\
9 & $079 / 2015$ & 19.2 & 84.3 & 0.2 & 1.1 & 0.54 & 0.54 \\
10 & $097 / 2015$ & 15.0 & 75.3 & 0.0 & 1.0 & 0.67 & 0.76 \\
11 & $098 / 2015$ & 16.0 & 72.4 & 0.0 & 1.0 & 0.67 & 0.76 \\
\hline
\end{tabular}

Table 3 presents the values for the Root Mean Square Error (RMSE) and Relative Error of the FRBS constructed for obtaining the components $\mathrm{N}$ and $\mathrm{E}$ from the PCO for the carrier waves $\mathrm{L1}$ and $\mathrm{L} 2$ using the data training sets (Tables 1 and 2).

Table 3: Values for the RMSE and RE of the FRBS obtained from training data.

\begin{tabular}{cccc}
\hline Carrier Wave & FRBS for the components & RMSE $(\mathrm{mm})$ & Relative Error \\
\hline \multirow{2}{*}{ L1 } & N & 0.56 & 0.37 \\
& E & 0.49 & 0.85 \\
L2 & N & 0.18 & 0.28 \\
& E & 0.19 & 0.55 \\
\hline
\end{tabular}

Note that the highest values for RMSE were $0.56 \mathrm{~mm}$ and $0.49 \mathrm{~mm}$; these values correspond respectively to the FRBS for the components $\mathrm{N}$ and $\mathrm{E}$ of the L1 carrier wave. The RMSE value for the FRBS of the remaining components was equal to or less than $0.19 \mathrm{~mm}$. In terms of relative error, the highest value was 0.85 for the FRBS of the carrier wave L1, and for the carrier wave L2, the highest value was 0.55 for the FRBS of components $E$.

After the selection of the FRBS obtained by ANFIS, it was possible to present the characteristics of the systems used to obtain PCO components. Figure 6 illustrates the fuzzification result of the input variables of the FRBS.

In the individual case of each of the variables (Figure 6), three membership functions were defined of the trapezoidal type, as these presented the best results from among the all types of tested membership functions. Each one of the functions is identified by a linguistic term that defines the state of each variable; the linguistic terms used were low, medium, high, low medium and high medium. Each linguistic term identifies a fuzzy set. The abscissa axis presents the domain ranges for each of the input variables and the ordinate axis the membership degree (Figure 6). 

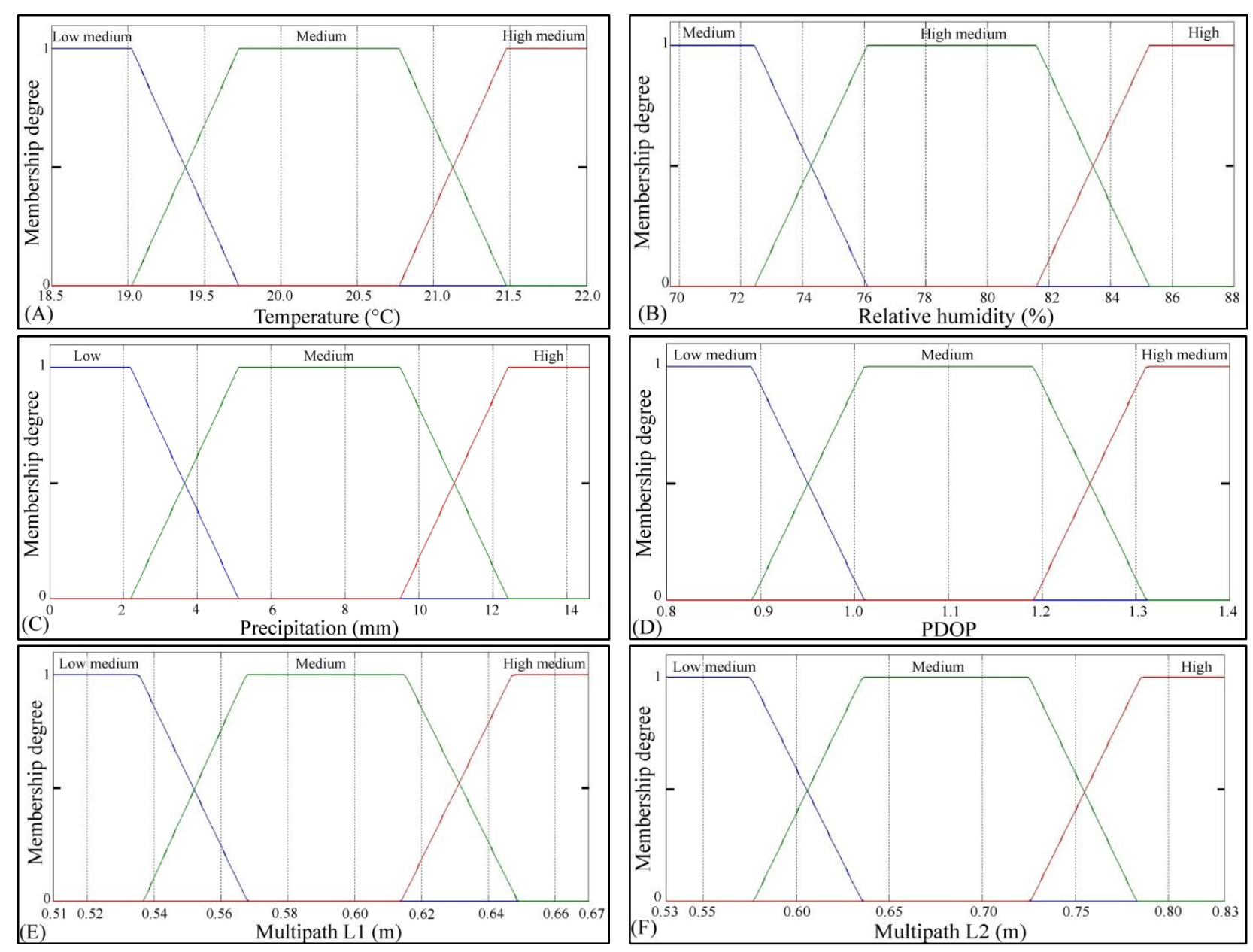

Figure 6: Fuzzification of the FRBS input variables.

Table 4 presents the verification data obtained by relative calibration in the field. Six of the calibration series performed were selected. The verification dataset will be taken as a reference for comparison with PCO components obtained by FRBS.

Table 4: Verification dataset (components of the PCO).

\begin{tabular}{cccccc}
\hline \multirow{2}{*}{ Series } & \multirow{2}{*}{ GPS day/year } & \multicolumn{2}{c}{ PCO components for L1 } & \multicolumn{2}{c}{ PCO components for L2 } \\
\cline { 3 - 6 } & & $\mathrm{N}(\mathrm{mm})$ & $\mathrm{E}(\mathrm{mm})$ & $\mathrm{N}(\mathrm{mm})$ & $\mathrm{E}(\mathrm{mm})$ \\
\hline V. 1 & $086 / 2015$ & 1.7 & -0.6 & -0.7 & 0.2 \\
V. 2 & $089 / 2015$ & 1.5 & -0.2 & -0.8 & 0.3 \\
V. 3 & $090 / 2015$ & 1.5 & -0.7 & -0.6 & 0.4 \\
V. 4 & $091 / 2015$ & 1.4 & -0.6 & -0.6 & 0.4 \\
V. 5 & $092 / 2015$ & 1.5 & -0.6 & -0.6 & 0.4 \\
V. 6 & $096 / 2015$ & 1.4 & -0.6 & -0.6 & 0.4 \\
\hline
\end{tabular}

Table 5 presents the meteorological data with PDOP as well the multipath effect in L1 and L2 obtained by calibration series and the TEQC software, respectively. These are the values of the FRBS input variables. 
Table 5: Verification datasets (meteorological variables, PDOP and multipath).

\begin{tabular}{|c|c|c|c|c|c|c|c|}
\hline \multirow[t]{2}{*}{ Series } & \multirow{2}{*}{$\begin{array}{c}\text { GPS } \\
\text { day/year }\end{array}$} & \multirow{2}{*}{$\begin{array}{c}\begin{array}{c}\text { Temperature } \\
\left({ }^{\circ} \mathrm{C}\right)\end{array} \\
\text { Average } \\
\end{array}$} & \multirow{2}{*}{$\begin{array}{c}\text { Relative } \\
\text { Humidity (\%) } \\
\text { Average } \\
\end{array}$} & \multirow{2}{*}{$\begin{array}{c}\text { Precipitation } \\
(\mathrm{mm})\end{array}$} & \multirow[t]{2}{*}{ PDOP } & \multicolumn{2}{|c|}{ Multipath (m) } \\
\hline & & & & & & MP (L1) & $M P(L 2)$ \\
\hline V. 1 & $086 / 2015$ & 21.4 & 76.33 & 14.0 & 1.1 & 0.65 & 0.64 \\
\hline V. 2 & $089 / 2015$ & 19.3 & 87.95 & 4.4 & 1.2 & 0.57 & 0.78 \\
\hline V. 3 & $090 / 2015$ & 20.1 & 69.68 & 6.5 & 1.1 & 0.52 & 0.53 \\
\hline V. 4 & $091 / 2015$ & 19.5 & 78.52 & 0.0 & 1.1 & 0.51 & 0.53 \\
\hline V. 5 & $092 / 2015$ & 19.0 & 73.20 & 0.0 & 1.0 & 0.65 & 0.83 \\
\hline V. 6 & 096/2015 & 18.1 & 73.45 & 0.0 & 1.1 & 0.54 & 0.56 \\
\hline
\end{tabular}

Table 6 presents the values of PCO components after the relative calibration and the FRBS for the carrier waves L1 and L2, along with the difference between the values of the components obtained by each of the methods and the standard deviation of the components for the sets of results obtained using relative calibration (Table 4) and FRBS. Noteworthy is that on the component $\mathrm{N}$, the smallest difference was for the datum $\mathrm{V}$. 2 with $0.11 \mathrm{~mm}$, for the component $\mathrm{E}$, the smallest difference was on the datum V. 2 and V. 6 with -0.29 and $1.61 \mathrm{~mm}$, respectively.

Table 6: Difference between the components obtained by the FRBS and relative calibration for L1 and L2

\begin{tabular}{|c|c|c|c|c|c|c|c|c|c|c|c|c|}
\hline \multirow{2}{*}{ V. } & \multicolumn{3}{|c|}{$\mathrm{N}$ L1 (mm) } & \multicolumn{3}{|c|}{$\mathrm{E} \mathrm{L1}(\mathrm{mm})$} & \multicolumn{3}{|c|}{$\mathrm{N}$ L2 (mm) } & \multicolumn{3}{|c|}{$E L 2(\mathrm{~mm})$} \\
\hline & $\mathrm{RC}$ & FRBS & Diff & $\mathrm{RC}$ & FRBS & Diff & $\mathrm{RC}$ & FRBS & Diff & $\mathrm{RC}$ & FRBS & Diff \\
\hline V. 1 & 1.70 & 1.40 & 0.30 & -0.60 & -0.36 & -0.24 & -0.70 & -0.52 & -0.18 & 0.20 & 0.17 & 0.03 \\
\hline V. 2 & 1.50 & 1.39 & 0.11 & -0.20 & -0.72 & 0.52 & -0.80 & -0.44 & -0.36 & 0.30 & 0.20 & 0.10 \\
\hline V. 3 & 1.50 & 0.55 & 0.90 & -0.70 & -0.10 & -0.60 & -0.60 & -0.40 & -0.20 & 0.40 & 0.10 & 0.30 \\
\hline V. 4 & 1.40 & 1.00 & 0.40 & -0.60 & -0.10 & -0.50 & -0.60 & -0.68 & 0.08 & 0.40 & 0.18 & 0.22 \\
\hline V. 5 & 1.50 & 0.90 & 0.60 & -0.60 & -0.20 & -0.40 & -0.60 & -0.55 & -0.05 & 0.40 & 0.19 & 0.21 \\
\hline V. 6 & 1.40 & 0.83 & 0.57 & -0.60 & -0.10 & -0.50 & -0.60 & -0.54 & -0.06 & 0.40 & 0.17 & 0.23 \\
\hline$\sigma$ & \pm 0.11 & \pm 0.33 & - & \pm 0.18 & \pm 0.25 & - & \pm 0.08 & \pm 0.10 & - & \pm 0.08 & \pm 0.03 & - \\
\hline
\end{tabular}

On Table 6, for the wave carrier $L 1$, note that component $N$ has the highest difference of $0.9 \mathrm{~mm}$ for the V.3. For this verification data, on Table 5, one notes that the value of the input variable relative humidity was $69.68 \%$. This input value is located at the beginning of the universe of this variable (Figure 6), which possibly led to a lower than expected result. The standard deviation was also verified for the set of results obtained by the relative calibration and FRBS, which were respectively, \pm 0.1 and $\pm 0.3 \mathrm{~mm}$.

In terms of component E, one notes from Table 6 that the data V. 3, V. 4 and V.6 present the same value as that obtained by FRBS. When the input data are verified for this component (Table 5 ), one notes that the multipath values were lower than the rest and present membership 1, or almost 1, in the Low medium set (Figure 6E), which indicates a higher level of influence from this variable on the final result (value of the component $E$ obtained by the FRBS). The standard deviation was verified for the set of results and was $\pm 0.2 \mathrm{~mm}$ for both methods.

For wave carrier L2 on Table 6, one finds the values obtained by relative calibration (Table 4) and FRBS for the PCO components for wave carrier L2. Note that for the components $N$ and $E$, the 
values from the differences between the two methods were equal or less than $-0.36 \mathrm{~mm}$. The data V. 4, V. 5 and V.6 present the smallest differences of the component $N$ with values of 0.08 , 0.05 and $-0.06 \mathrm{~mm}$, respectively. In terms of component $\mathrm{E}$, the smallest difference was on the $\mathrm{V}$. 1 with a value of $0.03 \mathrm{~mm}$.

For component $\mathrm{N}$, verification data was the only one that presented a positive difference. By studying the input data from the FRBS (Table 5), it was shown that the multipath variable (Figure 6F) influenced the result in an inverse fashion, that is, values with membership 1 on the Low Medium fuzzy set, present the highest values for the $\mathrm{N}$ component obtained by FRBS. Verification was also made showing that the standard deviation for the results obtained by relative calibration and FRBS were equal for both methods with a value of $\pm 0.1 \mathrm{~mm}$.

Although component E presented values practically equal to the results obtained with the FRBS, note that on Table 5, the input data does not present a tendency that indicates that the ANFIS performed the learning in an efficient manner. The established standard deviation for the results obtained for relative calibration was $\pm 0.1 \mathrm{~mm}$ and for FRBS $\pm 0.03 \mathrm{~mm}$.

Table 7 shows the results for the evaluation statistic of the average differences for each of the analyzed components found significance over T-student and ANOVA distributions with $\alpha=5 \%$.

Table 7: Statistics

\begin{tabular}{cccccc}
\hline & T-student & \multicolumn{3}{c}{ ANOVA } \\
\hline Components & L1 & L2 & Components & L1 & L2 \\
\hline N & 0.0663 & 0.0932 & $N$ & $P>0.0066$ & $P>0.0346$ \\
E & 0.1502 & 0.0645 & E & $P>0.0426$ & $P>0.0006$ \\
\hline
\end{tabular}

As shown on Table 7, the T-Student distribution is significant if the results are over the $\alpha$ value, as the ANOVA has positive significance if the results are under the $\alpha$ value. In both analyses the results shows the application SBRF could successfully model PCO deviations. In the evaluation of variability of the sample by ANOVA, significance was found for the horizontal residues in both carriers.

\section{Conclusions}

In this study, the ANFIS technique was applied, and which from a database identified the parameters of the FRBS, these in turn allowed for the obtainment of values for the components of the PCO. The criteria for choosing the FRBS were those that presented the lowest RMSE and RE values. For all the chosen FRBS that were based on these criteria, the trapezoidal membership function was used, as it was the type of function that presented the smallest deviations from among those functions tested. Furthermore, in relation to the quantity of membership functions, over all the performed tests, the best results were obtained when three functions were used per variable.

In order to evaluate the quality of the results obtained with the FRBS, a comparison is made of the PCO values obtained by the relative calibration (taken as real calibration values) with the values of the PCO obtained by means of the FRBS. The maximum tolerance value for this 
difference is $1 \mathrm{~mm}$ when comparing different methods for obtaining the PCO. Therefore, highlighted here is that for the planimetric components $\mathrm{N}$ and $\mathrm{E}$, the differences were equal to or less than $0.90 \mathrm{~mm}$.

Note that the input variable that most influenced the results was relative humidity of air followed by the temperature variable. The input variables temperature, relative humidity, precipitation, PDOD and multipath show themselves sufficient for modeling the horizontal components $\mathrm{N}$ and $\mathrm{E}$.

For future studies, it is recommended that specific software is used, where obtainment of the components by means of the FRBS is correlated, as in relative calibration. The study of new input variables in an attempt to decrease the difference of the values obtained by the modeling with real calibration values can also be performed. Furthermore, use can be made of data obtained over the course of the year, thus making the variable domains broader in relation to the data obtained from only from one part of the year, as which occurred in the process for obtaining the PCO components, where a dataset was used that was collected over the same period of the year (March and April 2015).

It is further recommended that data from other antennas is used, from other manufacturers and models. The creation of a databank of a set of antennas for the generation of FRBS by means of ANFIS can contribute to the improvement of this modeling. Finally, there is the goal of applying the values from the PCO obtained in this study, during the positioning processes with GPS and compare these to the same processing, while applying PCO values obtained from the relative calibration, thus verifying the influence of these PCO on the final coordinates.

\section{ACKNOWLEDGEMENT}

The first author acknowledge CNPq (Conselho Nacional de Desenvolvimento Científico e Tecnológico) for the doctoral scholarship granted during this research.

\section{REFERENCES}

Bystrov, D., \& Westin, J. 2015. Pratice. Neuro-Fuzzy Logic Systems. Matlab Toolbox GUI.

Ferreira, D. P. L., Jafelice, R. M., \& Serqueira, E. O. 2012. Using a fuzzy system in the study of the luminescence and potency of neodymium ions. Applied Optics, 51(28), pp.6745-6752. doi: 10.1364/AO.51.006745

Freiberger Junior, J. 2007. Investigação da calibração relativa de antenas GNSS. PhD. Federal University of Paraná.

Frevert, V. Stöcker, D. and Nuckelt, A. 2003. Beschleunigte Feldkalibrierung von GPS-Antennen. In: Proc. POSNAV 2003, pp.353-359.

Huinca, S. C. M. Krueger, C. P. 2011. Correlação das variáveis ambientais e efeito do multicaminho com os parâmetros de calibração (PCO) de antenas GNSS. In: Anais do VII Colóquio Brasileiro de Ciências Geodésicas. 12-14 September 2011. Curitiba, PR. 
Huinca, S. C. M. Krueger, C. P. 2012. Investigações preliminares das variáveis atmosféricas que podem influenciar na determinação dos parâmetros de calibração de uma antena GPS. In: Anais do IV Simpósio Brasileiro de Ciências Geodésicas e Tecnologias da Geoinformação. Recife: SIMGEO, pp.001-009.

Jang, J.-S. R. 1993. ANFIS: Adaptive-Network-Based Fuzzy Inference System. IEEE Transactions on Systems, Man, and Cybernetics, 23(3), 665-685. doi: 10.1109/21.256541

Jang, J-S. R. Sun, C-T. and Mizutani, E. 1997. Neuro-fuzzy and soft computing; a computational approach to learning and machine intelligence. Upper Saddle River: Prentice Hall. 614 p.

Krueger, C. P. Huinca, S. C. M. Leandro, D. and Viski, A. R. 2012. A inovação de produtos que contribuirão para o posicionamento por satélites com alta precisão. In: Anais do III Simpósio Brasileiro de Geomática, Presidente Prudente, SP, pp. 218-222.

Leick, A. (2004). GPS Satellite Surveying (3rd ed.). New York: John Wiley \& Sons.

Mader, G. L. 1999. GPS Antenna Calibration at the National Geodetic Survey. GPS Solutions, 3(1), pp.50-58. doi: 10.1007/PL00012780

Monico, J. F. G. (008. Posicionamento pelo GNSS: descrição, fundamentos e aplicações (2nd ed.). São Paulo: Editora UNESP.

Nardez, N. N. 2015. Obtenção do parâmetro PCO de antenas GNSS por meio de Sistemas Baseados em Regras Fuzzy. PhD. Federal University of Paraná.

Negnevitsky, M. 2005. Artificial Intelligence. A Guide to Intelligent Systems. 2nd ed. England: Addison Wesley.

Rocken, C. Meertens, C. Stephens, B. Braun, J. Vanhove, T. Perry, S. Rudd, O. Mccullum, M. and Richardson, J. 1995. UNAVCO Academia Research Infrastructure (ARI) Receiver and Antenna Test Report. University NAVSTAR Consortium Report, Bounder, Colorado, USA.

Rothacher, M. and Mader, G. 2002. Receiver and Satellite Antenna Phase Center Offsets and Variations. In: Network, Data and Analysis Center Workshop 2002, IGS Workshop, pp. 141-152, Ottawa.

Seeber, G. 2003. Satellite Geodesy: Foundations, Methods and Applications. Berlin, New York: Walter de Gruyter. doi: 10.1515/9783110200089

Souza, E. M., Polezel, W. G. C., \& Monico, J. F. G. 2005. Avaliação do Nível de Multicaminho no Posicionamento Relativo GPS e sua Atenuação Através da Análise de Multiresolução. Bulletin of Geodetic Sciences, 11(2), pp.221-234.

Takagi, T., \& Sugeno, M. 1985. Fuzzy Identification of Systems and its Applications to Modelling and Control. IEEE Transactions on Systems, Man, and Cybernetics, 15(1), pp.116-132. doi: 10.1109/TSMC.1985.6313399

Unavco, 2017. University NAVSTAR Consortium. TEQC Tutorial. [online] Available at: <https://www.unavco.org/software/data-processing/teqc/doc/UNAVCO_Teqc_Tutorial.pdf> [Accessed 8 May 2017].

Wanninger, L. and May, M. 2000. Carrier phase multipath calibration of GPS reference stations. In: Proceedings of the 13th International Technical Meeting of the Satellite Division of the Institute of Navigation, ION GPS 2000. Salt Lake City, UT, USA. 
Wübbena, G. Schmitz, M. Menge, F. Böder, V. and Seeber, G. 2000. Automated absolute field calibration of GPS-Antennas in real time. In: Proceedings of the Institute of Navigation ION-GPS 2000. Salt Lake City, UT, USA, September, pp.19-22.

Zadeh, L. A. (1965). Fuzzy Sets. Information and Control, 8(3), pp.338-353. doi: 10.1016/S00199958(65)90241-X

Zeimetz, P. and Kuhlmann, H. 2008. On the Accuracy of Absolute GNSS Antenna Calibration and the Conception of a New Anechoic Chamber. GNSS Antenna Calibration and Accuracy Assessment. In: Proceedings of the FIG Working Week, Stockholm, Sweden, June, pp. 1-16. 